\title{
REVIEW
}

\section{Clinical translation of human neural stem cells}

\author{
Ann Tsukamoto*, Nobuko Uchida, Alexandra Capela, Thorsten Gorba and Stephen Huhn
}

\begin{abstract}
Human neural stem cell transplants have potential as therapeutic candidates to treat a vast number of disorders of the central nervous system (CNS). StemCells, Inc. has purified human neural stem cells and developed culture conditions for expansion and banking that preserve their unique biological properties. The biological activity of these human central nervous system stem cells (HuCNS-SC ${ }^{\circledR}$ ) has been analyzed extensively in vitro and in vivo. When formulated for transplantation, the expanded and cryopreserved banked cells maintain their stem cell phenotype, self-renew and generate mature oligodendrocytes, neurons and astrocytes, cells normally found in the CNS. In this overview, the rationale and supporting data for pursuing neuroprotective strategies and clinical translation in the three components of the CNS (brain, spinal cord and eye) are described. A phase I trial for a rare myelin disorder and phase I/II trial for spinal cord injury are providing intriguing data relevant to the biological properties of neural stem cells, and the early clinical outcomes compel further development.
\end{abstract}

\section{Background}

StemCells, Inc. was formed with the charter of discovering tissue-derived stem cells using the monoclonal antibody-based high speed cell sorting technology platform, previously used for purification of hematopoietic stem cells and peripheral nervous system stem cells [1-4]. More recently, this technology has been used to identify and purify other tissue stem cells, including hair follicle and skin [5], intestinal [6], muscle [7] and cancer stem cells $[8,9]$. This technology can also be applied to the purification of multi-potent stem cell populations derived from embryonic or induced pluripotent stem cells to eliminate teratogenic precursors. The company employed this strategy to prospectively purify its human

\footnotetext{
* Correspondence: Ann.tsukamoto@stemcellsinc.com

StemCells, Inc., 7707 Gateway Blvd, Newark, CA 94560, USA
}

central nervous system stem cell ( $\left.\mathrm{HuCNS}-\mathrm{SC}^{\circ}\right)$ population for expansion as neurospheres and banking. In this overview, the preclinical data are summarized and rationale provided for advancing these cells into clinical trials involving the brain, spinal cord, and eye.

A seminal finding in advancing regenerative medicine for human neurological disorders was the demonstration that neurogenesis occurs in the human adult brain $[10,11]$. This discovery, coupled with the identification and expansion of human neural stem cells by our laboratory and others [12-18], has led to a plethora of studies investigating neuroplasticity and regeneration. Though still early, a growing body of data suggests that human neural stem cells or their progenitors might one day repair or replace cells within the diseased or damaged central nervous system (CNS).

The translation of HuCNS-SC to clinical testing has been facilitated by prospective identification, reproducible expansion into cell banks, and stability upon cryopreservation. The availability of small animal models relevant to a range of human conditions has further facilitated efficacy testing and investigation of potential mechanisms of action. Moreover, past experience with cell and tissue transplants into the brains of Parkinson's or Huntington's patients (reviewed in [19-21]) has provided insights into allogeneic long-term survival in the relative immune-privileged niche of the CNS and has paved the way for studies with neural stem and/or progenitor cell products.

\section{About the human central nervous system stem cells}

The existence of both mouse and human neural stem cells has been demonstrated by multiple laboratories through growth in tissue culture systems and multi-lineage differentiation in fate mapping studies of cultured cells [22-27]. In 2000, scientists at StemCells, Inc. purified HuCNS-SC $[16,28]$, an adult, tissue-specific stem cell. Each HuCNSSC bank is created from purified human neural stem cells from a single fetal brain tissue (16 to 20 weeks gestation) using an isolation protocol involving monoclonal antibodies to cell surface markers and high-speed cell sorting. 
The cell expresses high levels of CD133 and low levels of CD24 $\left(\mathrm{CD} 133^{+} / \mathrm{CD} 24^{-/ \mathrm{lo}}\right)$ and lacks expression of the hematopoietic lineage markers CD45 or CD34. Single

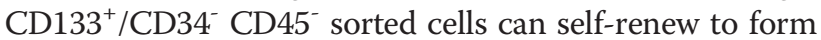
neurospheres with multi-potentiality, hence the qualification as a 'stem cell'. When the $\mathrm{CD} 133^{+} / \mathrm{CD} 24^{-/ \mathrm{lo}}$ cells are grown under defined conditions [15], long-term expandable neurosphere cultures are established. Karyotype and morphological stability have been demonstrated with more than ten passages and in long-term culture. This method of cell isolation and culture has allowed for reproducible generation of human neural stem cell banks. For human clinical application, brain tissues are procured through an approved non-profit tissue procurement agency according to the Good Tissue Practice requirements of the US Food and Drug Administration (FDA).

Differentiation of these cells in vitro delineates their multipotency to become astrocytes, oligodendrocytes and different neuronal subtypes [29]. When induced in vitro by stimulating media additives, HuCNS-SC show a significant increase in migratory and phagocytic activity as assessed by a quantitative assay of in vitro cell function (Figure 1). Moreover, in vivo analysis of HuCNS-SC transplants into the brain of immunodeficient mouse models show that the cells seed the neurogenic niche of the subventricular zone, slowly divide, and migrate through different portals, including the rostral migratory stream to the olfactory
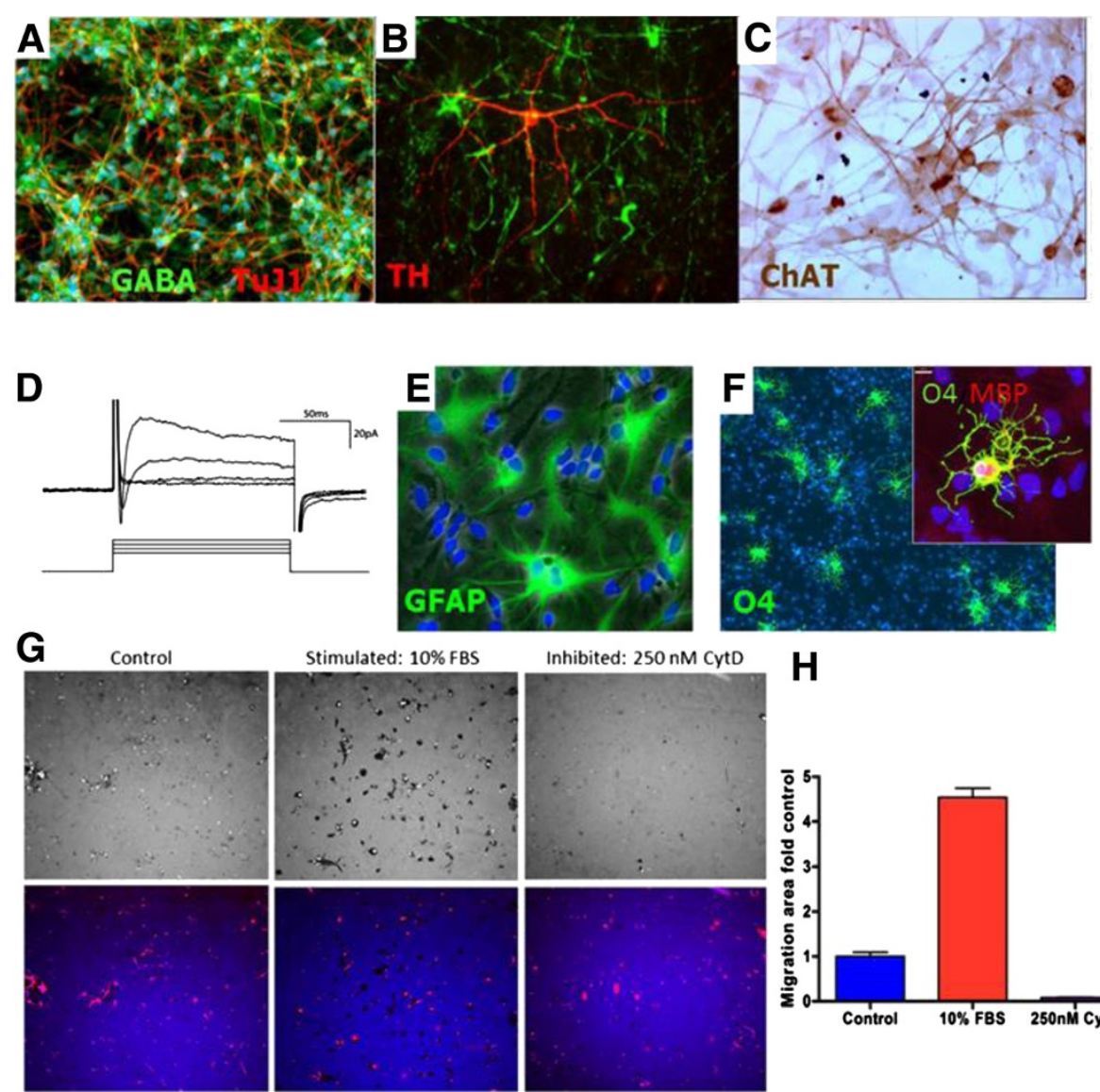

Stimulated: $10 \%$ FBS
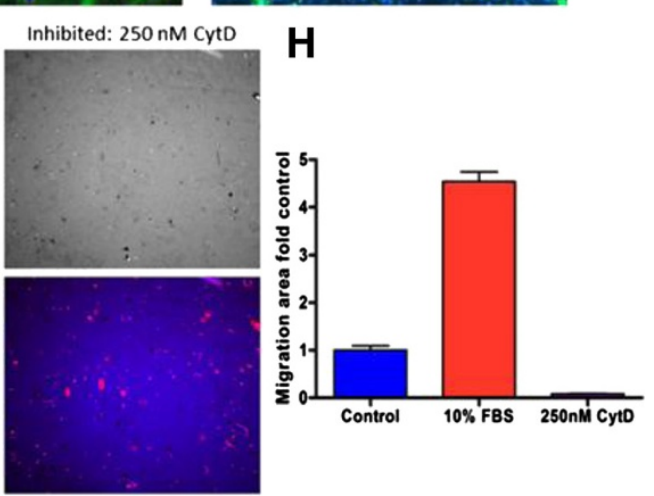

Figure 1 Human central nervous system stem cell (HuCNS-SC) differentiation in vitro. Human cells plated in culture become specific neuronal subtypes under defined growth factor conditions. (A) Gabaergic (gamma-aminobutyric acid, GABA); (B) dopaminergic (tyrosine hydroxylase; TH); (C) cholinergic (choline acetyltransferase; ChAT). (D) Differentiated neurons mature in vitro as shown by voltage-activated sodium and potassium currents from a clamp recording. Adapted from [29]. (E,F) HuCNS-SC also differentiate into astrocytes as defined by glial fibrillary acidic protein (GFAP; E) or oligodendrocytes identified by the marker $\mathrm{O} 4$ (F). In culture, rare oligodendrocytes can mature to myelin basic protein (MBP)-positive cells (inset of F). (G) Images of fluorescent bead lawn in which tracks cleared of beads by migrating/phagocytosing HUCNS-SC appear as black and beads ingested by the cells appear as bright spots (upper panel), and composite images of beads in blue and phalloidin stained cells in red (lower panel). Cells located within cleared track areas (red in lower panel) co-localize with bright spots of phagocytosed beads in upper panel. (H) Quantification of migration area (fluorescent beadfree) with high-content assay analysis software. Factors in fetal bovine serum (FBS) significantly enhanced migratory/phagocytosing activity, while it was blocked by the actin polymerisation inhibiting reagent cytochalasin $\mathrm{D}(\mathrm{CytD})$. Data represents the results of three independent experiments in triplicate wells. 
system (Figure 2). Long-term engraftment ( $>24$ weeks) shows global CNS migration and multi-lineage differentiation (astrocytes, oligodendrocytes, and neurons) in a site-specific manner (Figure 3). These in vivo characteristics have formed the basis for initiation of translational studies in select human CNS disorders, discussed below. The company intends to develop the $\mathrm{HuCNS}-\mathrm{SC}$ as an allogeneic cell therapy for specific CNS disorders based on both neuroprotective and neuronal replacement strategies.

\section{Disease targets}

Treating disorders of the CNS has been one of the most challenging areas of modern medicine. Conventional drugs alleviate some symptoms but rarely modify the disease course or halt progression, particularly in neurodegenerative conditions. Regenerative medicine using defined stem or progenitor cells offers the potential to prevent further cell loss (that is, neuroprotection) and/or replace damaged or lost neurons (that is, neuronal replacement). Furthermore, both neuroprotective and neuronal replacement strategies can be envisioned in chronic neurodegenerative (for example, age-related macular degeneration and Alzheimer's disease) and genetic neurodegenerative diseases (for example, neuronal ceroid lipofuscinosis (Batten), leukodystrophies (Pelizaeus-Merzbacher)), as well as injuries to the CNS (for example, spinal cord injury (SCI), stroke and traumatic brain injury). Neuronal cell replacement, as attempted in treating Parkinson's disease, is particularly challenging because of the requirement to restore a precise neuron type in a specific location with proper integration and connectivity into a functional network. Thus, a neuroprotection strategy was envisioned as a more attainable goal for first in-human clinical studies using human neural stem cells. In this regard, StemCells, Inc. is actively engaged in testing HuCNS-SC in several target indications (Table 1).
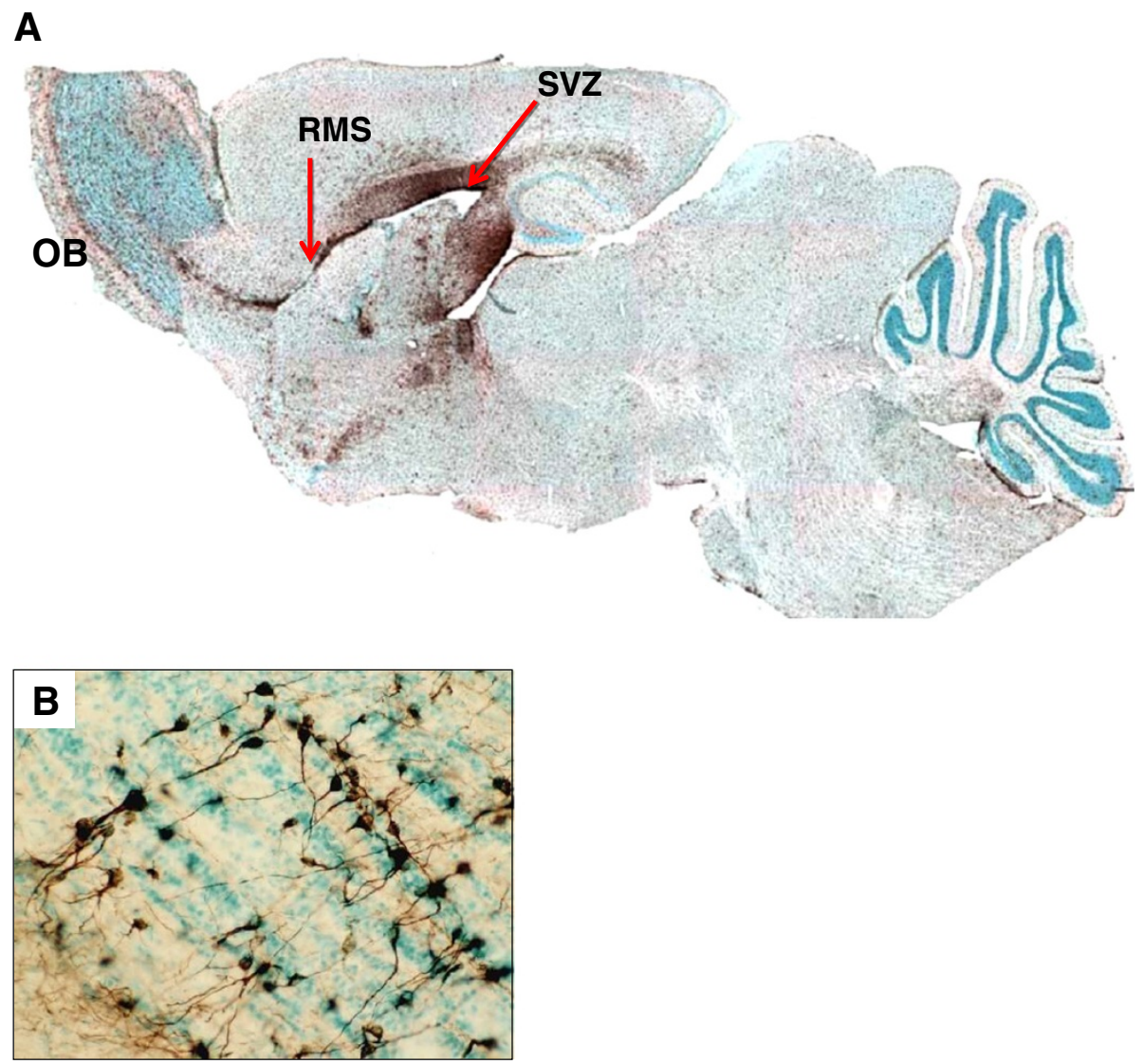

Figure 2 Long-term engraftment and global migration of human central nervous system stem cells. (A) Saggital section of a NOD-SCID mouse brain transplanted as a neonate with human central nervous system stem cells (HuCNS-SC). Human cells were detected by immunoperoxidase staining with a human specific monoclonal antibody, STEM121 (brown), which demonstrates long-term engraftment and global migration within the brain. After transplantation into the lateral ventricles, human cells reside primarily in the neurogenic niche of the subventricular zone (SVZ). Migration radially from the SVZ is observed, including through the rostral migratory stream (RMS) to the olfactory bulb (OB). Local host signals define the predominant maturational outcomes of the cells. (B) Differentiation of HuCNS-SC to granular neurons in the olfactory bulb. 

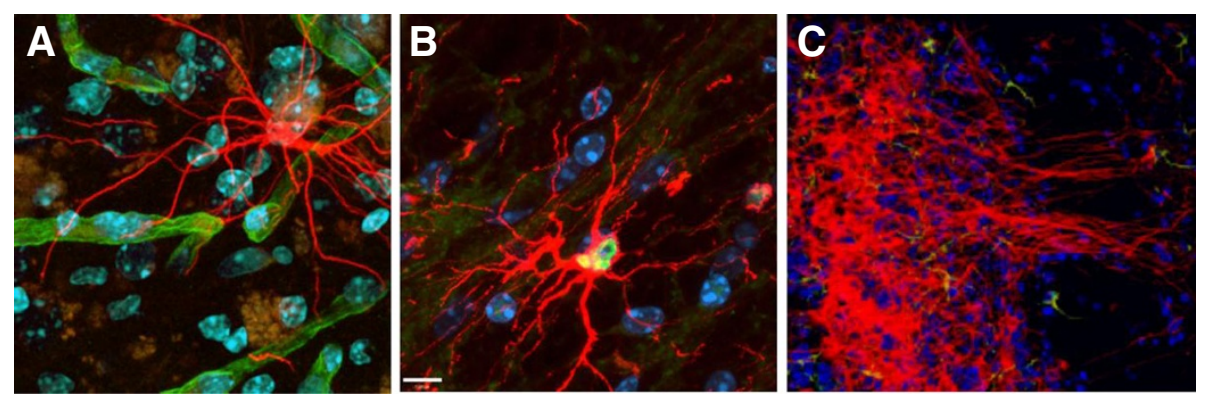

Figure 3 Human central nervous system stem cells (HuCNS-SC) preferentially differentiate to specific lineages depending upon their site of migration. Transplanted HuCNS-SC or their progeny were detected by staining using human-specific antibodies. Cell lineage was determined by morphology or co-staining for lineage markers. (A) Human astrocytes (STEM123, hGFAP, red) are observed juxtaposed to mouse blood vessels (beta-dystroglycan, green). (B) Human oligodendrocytes (Olig 2; green; STEM121 red) were confined to white matter areas such as the corpus collosum. (C) Within the olfactory system, human cells differentiate to granular neurons with long axons (STEM 121, red).

\section{Disease targets for neuroprotective and neuronal replacement strategies}

Neuroprotection of host cells can result from several mechanisms, including provision of neurotrophic, angiogenic, immune modulating factors and/or other proteins required for maintenance of healthy neurons. Protection of host neurons can also result from remyelination from new oligodendrocytes. Neuronal replacement strategies aim to replace specific lost or deficient cells, such as in Parkinson's disease. The key attributes of neural stem cells - such as self-renewal to provide a continuous reservoir of factor-producing cells, global CNS migratory properties, and their innate ability to form new normal neurons, astrocytes or oligodendrocytes - position them as attractive novel therapeutics for treating the plethora of neurodegenerative conditions. The translational approach was to first test the neuroprotective properties of the stem cell in the initial introduction to human testing while continuing to accumulate more complex preclinical data supporting neural replacement strategies. The first application of HuCNS-SC as a therapeutic candidate evaluated its safety and preliminary efficacy as a cell-based enzyme delivery system in a neurodegenerative lysosomal storage disease (LSD).

\section{Lysosomal storage diseases affecting the central nervous system}

LSDs result from recessive mutations in genes encoding soluble enzymes or structural proteins causing lysosomal dysfunction, accumulation of insoluble storage material, and eventual cell death. Development of effective therapies for the neuropathic LSDs, such as enzyme replacement, is challenged by the presence of the blood-brain barrier, which limits accessibility of intravenously delivered soluble enzyme to the brain. Direct intrathecal and intracisternal delivery of enzyme, protein modifications (such as lipidization and receptor targeting), nanotechnologies, as well as cell-based delivery schemes are all being tested for more effective transport of proteins and drugs to the CNS but currently no strategy has hit a

Table 1 Overview of HuCNS-SC clinical translation programs for central nervous system disorders

\begin{tabular}{|c|c|c|c|}
\hline $\begin{array}{l}\text { CNS } \\
\text { area }\end{array}$ & Disease/injury & Stage & Outcome \\
\hline \multirow[t]{4}{*}{ Brain } & $\begin{array}{l}\text { Neuronal ceroid lipofuscinosis (Batten } \\
\text { disease): infantile and late-infantile }\end{array}$ & $\begin{array}{l}\text { Phase I } \\
\text { completed }\end{array}$ & $\begin{array}{l}\text { Safety, feasibility and tolerability of HuCNS-SC transplants. Post-mortem evidence of } \\
\text { long-term donor cell survival in post-mortem } 3 / 6 \text { subjects alive } 5 \text { years post- } \\
\text { transplant }\end{array}$ \\
\hline & & $\begin{array}{l}\text { Phase lb } \\
\text { suspended }\end{array}$ & No accrual of eligible subjects \\
\hline & Pelizaeus-Merzbacher myelin disorder & $\begin{array}{l}\text { Phase I } \\
\text { completed }\end{array}$ & MRI evidence of donor-derived myelin and modest gains in neurological function \\
\hline & Alzheimer's disease & Preclinical & Enhanced synaptic function and restored memory in two AD relevant models \\
\hline \multirow[t]{2}{*}{$\begin{array}{l}\text { Spinal } \\
\text { cord }\end{array}$} & Thoracic spinal cord injury & $\begin{array}{l}\text { Phase } \mathrm{I} / \mathrm{II} \text { in } \\
\text { progress }\end{array}$ & Sensory gains observed in first cohort. \\
\hline & Cervical spinal cord injury & Preclinical & Improve motor function in $\mathrm{SCl}$ mice \\
\hline Eye & Age related macular degeneration & $\begin{array}{l}\text { Phase } I / I I \text { in } \\
\text { progress }\end{array}$ & Subject accrual ongoing \\
\hline
\end{tabular}


home-run [30]. The concept of using neural stem cells for the delivery of normal proteins to replace those that are defective or absent was proposed to take advantage of the inherent properties of these cells (reviewed in [31]). Their long-term integration and global distribution throughout the brain parenchyma comprise a mechanism to deliver therapeutic proteins in a direct and sustained manner. Several studies have examined the effect of normal or genetically engineered neural stem cells in specific animal models of LSDs [32-39] and shown these to be viable therapeutic strategies worthy of further investigation.

\section{Neuronal ceroid lipofuscinoses}

Of the numerous LSDs, neuronal ceroid lipofuscinoses (NCLs; commonly referred to as Batten disease) exhibit disease pathogenesis predominantly within the CNS. NCLs comprise the most prevalent group of neurodegenerative LSD and consist of at least ten genetically distinct forms. The infantile (CLN1, palmitoyl-protein thioesterase, PPT-1 enzyme deficiency) and late-infantile (CLN2, tripeptidyl-peptidase I, TPP-I enzyme deficiency) genetic subtypes result from gene mutations in soluble lysosomal enzymes $[40,41]$ causing accumulation of lipofuscin material in neurons and eventual cell death. Knockout mouse models for the infantile (PPT1-/-) [42] and late-infantile (TPP-I) [43] forms develop progressive and severe neurodegeneration and recapitulate the pathology of the human diseases. As predicted, in vitro preclinical studies show HuCNS-SC-based cross-correction of enzyme deficiency through PPT-1 uptake via the mannose 6-phosphate receptor in cultured PPT-1deficient mouse and human fibroblasts [38]. In order to create a suitable xenotransplantation model for testing the long-term effects of HuCNS-SC, the PPT-1 knockout mouse was backcrossed to the immune deficient NODSCID mouse. Transplantation of HuCNS-SC in the PPT1 knockout/NOD-SCID brain results in engraftment, migration and a region-specific differentiation pattern similar to that observed in non-neurodegenerative NOD-SCID animals. The HuCNS-SC transplanted mice showed production of functional PPT1 enzyme in whole brain extracts and statistically significant reduction in lipofuscin levels, ranging from $31 \%$ in the cortex to $>50 \%$ in the hippocampus and cerebellum. The reduction in storage material correlated with observed protection of hippocampal neurons (up to $57 \%$ of CA1 and $97 \%$ of $\mathrm{CA} 2 / 3$ ) and up to $77 \%$ of cortical neurons. The neuroprotective effects of HuCNS-SC transplants through cell-based enzyme cross-correction also delayed the loss of motor function. These data provided the rationale for the first in-human trials using these purified and expanded, allogeneic human neural stem cells.
A phase I open label clinical study was conducted at Oregon Health and Science University by Drs Robert D Steiner and Nathan Selden to evaluate the safety of allogeneic HuCNS-SC administration [44]. The study enrolled six subjects; two with infantile (INCL) and four with late-infantile (LINCL) disease confirmed by detection of mutations in the PPT-1 or TPP-I genes, respectively. Additionally, to consider the equipoise of this first in-human trial, only subjects with severe cognitive (developmental age less than two-thirds of chronological age) and neurological symptoms (significant cerebral atrophy, enlarged ventricles, and marked neurological and neuropsychological impairment) consistent with a very advanced stage of disease were enrolled (Figure 4). The study examined the tolerability of direct neurosurgical implantation into bilateral subcortical and ventricular sites at two dose levels; 500 million or 1 billion cells. The subjects received immunosuppression until the end of the safety study at 12 months. The study revealed the safety of the intervention and transplantation of the cells. At study termination, all remaining subjects consented to participate in a 4-year long-term follow-up protocol, which completed in January 2013. During the trial, one subject died approximately 1 year posttransplantation from causes related to underlying

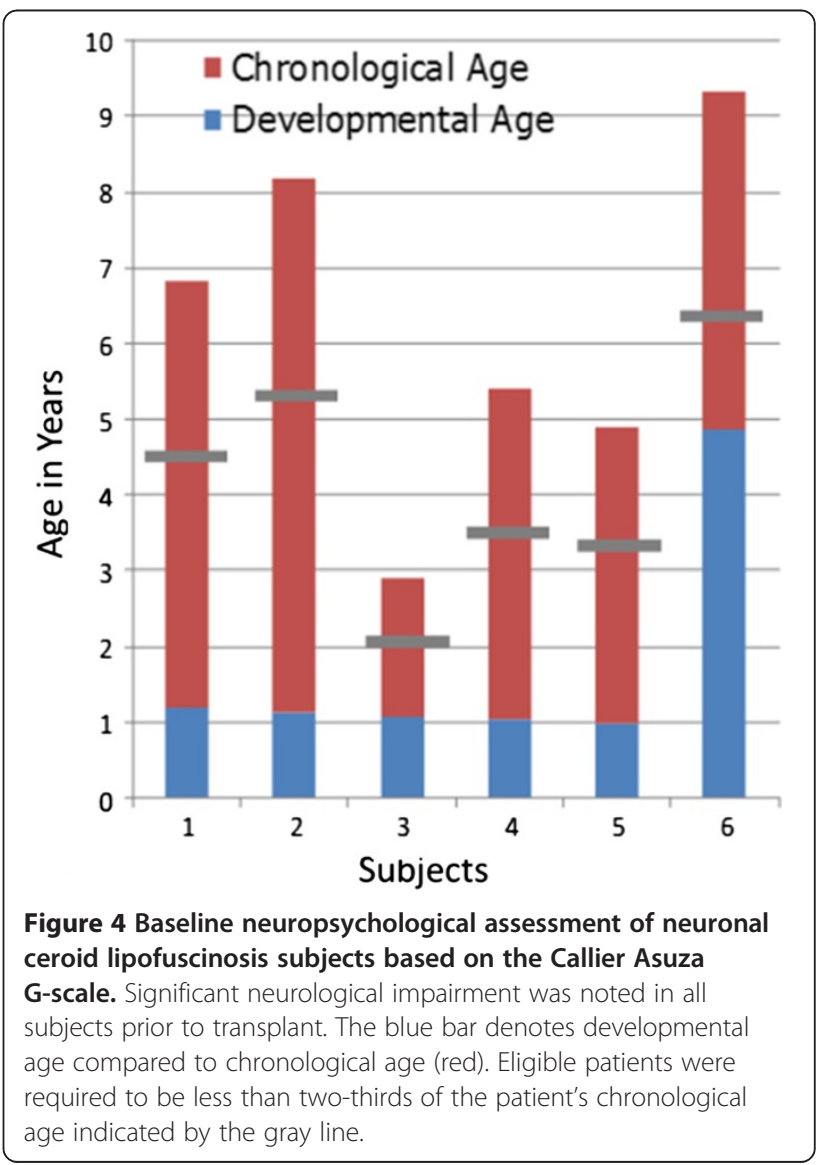


disease. Two subjects succumbed to their disease during the long-term follow-up study. All families consented to a post-mortem brain examination that revealed severe atrophy consistent with NCL. No adverse histopathological effects on the transplanted HuCNS-SC, such as neoplasia, cystic structures, or immune cell infiltration, were apparent. A molecular analysis was performed on several samples from the post-mortem brains using quantitative PCR analysis to identify the presence of donor cells by histocompatibility antigen differences. Samples were selected from different brain regions to include sites adjacent to and remote from transplant sites. Donor cells were detected in the brains of two subjects, demonstrating long-term survival up to 2.5 years posttransplant and 1.5 years after immunosuppression was stopped. In addition, the distribution of donor-positive samples indicates that these human neural stem cells had migrated away from the transplant sites [44,45]. Demonstration of HuCNS-SC migration within the brain is important when considering future treatment strategies for global and diffuse neurodegenerative diseases such as Alzheimer's disease. The potential of HuCNS-SC to migrate and react to motility-enhancing and chemoattractive stimuli was demonstrated in vitro by an array of migration assay systems, one of which is shown as an example in Figure 1.

This clinical trial represents the first demonstration that purified, expanded and cryobanked, allogeneic human neural stem cells can be safely transplanted directly into the brain and are well tolerated in severely afflicted pediatric subjects. Neuropsychological outcomes did not show improvement in the subjects with refractory disease, and alterations in disease course could not be determined in this uncontrolled study. It was noted, however, that patients with the most cerebral atrophy and neurological disability continued to decline whereas those less impacted showed stability [44]. Moreover, the 4-year follow-up of the remaining subjects continues to show a satisfactory safety profile with no emerging safety concerns.

For a neuroprotective strategy to show meaningful clinical outcomes, sufficient numbers of functional host cells must exist at the time of intervention, hence the need to transplant subjects earlier in their disease course. A phase Ib trial in NCL was initiated to examine safety in subjects with early disease and also to determine the impact of HuCNS-SC transplantation on disease progression. The study was suspended before enrolling any subjects due to a lack of available study candidates with less pronounced neurodegeneration at presentation. Of the 22 potential subjects for possible screening, none met the inclusion criteria for the trial. The inability to accrue subjects in clinical trials for rare diseases is a challenge at best, as identifying those earlier in the disease course is compounded by significant delays in proper diagnosis. Establishment of more rapid methods to diagnose genetic diseases in newborns [46] is needed to shorten times to diagnosis and clinical decision making for relevant treatment options.

\section{Myelin disorders}

Normal function of the nervous system requires formation and maintenance of the myelin sheath, the insulating layer surrounding nerve axons required for rapid conduction of electrical impulses and axonal integrity. Dysfunction or loss of myelin can lead to severe deficits in neurological function as seen in the leukodystrophies, multiple sclerosis, stroke, and traumatic brain and SCIs. One strategy to preserve neuronal function is through provision of new myelinating oligodendrocytes and supportive astrocytes derived from neural stem cells [47] or glial progenitor cells (reviewed in $[48,49]$ ).

Several animal models exist for testing treatment options for myelin disorders, each possessing unique attributes or aspects reflective of the human afflictions (reviewed in [50]). The myelin basic protein (MBP)deficient shiverer (Shi) mouse is a dysmyelination model widely used to assess myelin production by donor cells [51-56]. The Shi mouse has been crossed to immunodeficient strains to facilitate analysis of transplanted human xenografts $[47,53,54,57,58]$. De novo myelin production from human oligodendrocytes has been observed in the brains of immunodeficient Shi mice (Shi-id) or contused SCI NOD-SCID mice transplanted with HuCNS-SC [47,54]. In these studies, immunohistochemical staining demonstrated that host mouse axons were ensheathed by human myelin derived from transplanted HuCNS-SC. Generation of compact myelin in the injured spinal cord correlated with improved motor function and in the Shiid brain restored CNS conduction velocity in animals transplanted as asymptomatic neonates or symptomatic hypomyelinated juveniles. Moreover, ex vivo magnetic resonance imaging (MRI) of transplanted Shi-id brains detected changes in water diffusivity consistent with increased myelination. In the rodent brain, robust human MBP expression is observed at approximately 6 weeks after HuCNS-SC transplantation [47]. Thus, while other myelin mutant models of human diseases exist, such as the proteolipid protein (PLP) mutants reflective of Pelizaeus-Merzbacher disease (PMD), their shortened life span precludes assessment of the robustness and longevity of neural stem cell-based therapies. The preclinical demonstration of de novo myelination from transplanted HuCNS-SC in the Shi-id mouse and the contused SCI NOD-scid mouse provided the rationale to obtain FDA authorization for a phase I/II study in PMD.

PMD is a rare fatal leukodystrophy resulting from mutations of the X-linked gene encoding PLP1, the major 
protein of the CNS myelin sheath. PLP1 mutations produce a spectrum of neurological symptoms ranging from severe, or connatal form, to classical, or the milder spastic paraplegia, all resulting from failure to produce functional myelin either due to apoptosis of the oligodendrocytes or abnormal myelin formation [59]. In the most severe connatal group, clinical signs of PMD can present at birth or within the first few weeks as nystagmus (uncontrolled rapid eye movements), difficulty breathing and low muscle tone (hypotonia). The subjects often require a tracheostomy to assist in airway management and a gastrostomy tube shortly after birth. Neurological and developmental milestones are either delayed or never achieved. Patients have severe motor and language impairment, which generally progresses. The onset of severe spasticity can be seen in later childhood. MRI reveals diffuse hypomyelination of both cerebral hemispheres, brainstem and cerebellum. There are no therapeutic options for patients with PMD; only supportive and palliative treatments are available. Death usually occurs within the first decade of life.

A phase I open label study was conducted in four subjects with severe connatal PMD to evaluate the safety and clinical effects of HuCNS-SC transplants into the neurodegenerative, hypomyelinated brain. The trial was conducted by Drs David Rowitch and Nalin Gupta at the University of California, San Francisco. Subjects were all male with confirmed PLP1 mutations, MRI absence of myelin and clinical symptoms consistent with early, severe PMD [60]. Each subject received a total brain dose of 300 million cells through injections into the frontal white matter area of each hemisphere. Immunosuppression was administered for the first 9 months after transplantation. Analysis of safety parameters, including physical and neurological examinations, did not reveal any adverse or serious adverse events considered related to HuCNS-SC transplants. MRI assessments did not show signs of inflammation, gliosis, ischemia, or cystic or neoplastic changes. Diffusion tensor imaging, a noninvasive MRI imaging technique that can measure water diffusivity in the brain, was used as a surrogate to evaluate myelin development in these subjects over time. Decreases in the mean and radial diffusivity (perpendicular to the axon) coupled with increases in fractional anisotropy (FA) are indices of white matter integrity. In each of the four subjects, regions of interest within the corona radiata were examined by these techniques and compared to control regions remote to the transplant sites. The two older subjects ( 2 and 4 ) showed the most pronounced increase in FA and decrease in radial diffusivity consistent with new myelin formation. The younger subjects, 1 and 3, also showed increases in FA but were more variable possibly reflective of less mature brain. Table 2 summarizes some of the key clinical and radiological observations by individual subject in the phase I PMD study. Twelve month neurological examinations showed either stable or modest gains in motor or cognitive function in all subjects compared to pre-transplant assessments. Subject 4 had the most pronounced changes, including the ability to follow two-step commands and speak audible words, improved truncal support and development of the ability to take steps with assistance. Neuropsychological assessments also showed small but measurable gains in select subtests. These gains, though modest, are not expected for a progressive, severe neurodegenerative disease. Further testing in a

Table 2 Major neurological and MRI diffusion changes, by subject, for the phase I trial in Pelizaeus-Merzbacher disease

\begin{tabular}{|c|c|}
\hline Subject & Neurological and radiological changes \\
\hline \multirow{3}{*}{$\begin{array}{l}\text { Subject } 1 \text { ( } 16 \mathrm{~m} \text { of age at } \\
\text { transplant) }\end{array}$} & Tracheostomy and gastrostomy at baseline \\
\hline & Remained neurologically stable, but was noted to have reduced nightly CPAP at 12 months \\
\hline & Increased FA by MRI \\
\hline \multirow[t]{2}{*}{$\begin{array}{l}\text { Subject } 2 \text { ( } 42 \mathrm{~m} \text { of age at } \\
\text { transplant) }\end{array}$} & $\begin{array}{l}\text { Developed improved truncal support and the ability to take steps with assistance. He also began speaking audible } \\
\text { single words and the ability to follow two-step commands }\end{array}$ \\
\hline & Increased FA by MRI \\
\hline \multirow{4}{*}{$\begin{array}{l}\text { Subject } 3 \text { ( } 14 \mathrm{~m} \text { of age at } \\
\text { transplant) }\end{array}$} & Tracheostomy and gastrostomy at baseline \\
\hline & Developed upper extremity antigravity strength and to take some solid foods by mouth \\
\hline & Nightly CPAP dependency reduced \\
\hline & Greatest increase in FA by MRl; but comparable to 'control' regions \\
\hline \multirow[t]{3}{*}{$\begin{array}{l}\text { Subject } 4 \text { ( } 66 \mathrm{~m} \text { of age at } \\
\text { transplant) }\end{array}$} & $\begin{array}{l}\text { Developed improved truncal support and progressed from the use of a walker with significant support at baseline to } \\
\text { walking with minimal assistance }\end{array}$ \\
\hline & Developed the ability for self-feeding and to follow two-step commands \\
\hline & Increased FA by MRI \\
\hline
\end{tabular}


controlled study will be required to demonstrate clinical efficacy of HuCNS-SC transplantation for leukodystrophies such as PMD and other myelin diseases.

\section{Spinal cord injury}

Traumatic SCI results in localized destruction of neural tissue from the primary injury followed by secondary injury from inflammation, immune responses and cell apoptosis. These events result in oligodendrocyte death and axonal loss in white matter and neuronal loss in gray matter. Neural stem cell transplantation for SCI represents a unique opportunity to assess an inherent multipronged therapeutic strategy that demonstrated improvement in locomotion in preclinical animal models. Human neural stem cells can provide neuroprotection through provision of secreted neurotropic and angiogenic factors and/or reformation of myelin sheaths from stem cell-derived oligodendrocytes for maintenance of axonal integrity. The transplanted neural stem cells may also contribute to neuroreplacement by differentiating neurons capable of creating synaptic contacts to re-establish bridging circuitry between new neurons and host cells [54].

Our collaborators at the University of California, Irvine, Drs Anderson and Cummings, developed thoracic SCI models in immunodeficient mice to examine the efficacy, mechanism of action, and long-term survival of HuCNS-SC transplants into subacute or chronic injured cords [54,61-63]. The cumulative data spanning approximately 10 years shows that HuCNS-SC transplanted directly into the cord above and below the epicenter of injury restored locomotor function in subacute and chronic SCI mice. Analysis of transplanted spinal cords by dual histochemical staining for human cells and lineage markers showed robust engraftment, migration and differentiation to neurons (26 to $38 \%$ ), astrocytes (3 to $8 \%$ ) and oligodendrocytes (48 to 64\%) $[54,63]$. Immunoelectron ultrastructural analysis reveals the formation of compact myelin sheaths by human oligodendrocytes as well as human neurons with synaptic vesicles juxtaposed to host neurons. These results suggest that multiple mechanisms of action may be contributing to functional recovery in these animals. Although the ability to dissect this question remains challenging, one clue to potential mechanisms of action comes from selective ablation of the human cells using diphtheria toxin, which abrogates the regained motor function. This study shows the requirement for continued integration and survival of human cells to maintain restored motor function. Thus, the therapeutic effects of HuCNS-SC seen in SCIs and a hypomyelination disease results from stable integration of newly formed neural cells, in particular myelin-producing oligodendrocytes. In fact, these cells likely impart their full therapeutic potential as a result of both integration and function, as well as provision of neurotrophic support. Another important aspect of these studies was the lack of induced allodynia (abnormal sensitivity to pain) following HuCNS-SC transplantation. These results contrast with those previously reported [64] in which neural stem cell transplants led to functional recovery of hind limbs but development of hypersensitivity (allodynia) in the forepaws due to axonal sprouting. Differences in cell source, animal models and culture methods preclude identification of specific parameters that contribute to the undesired outcome in their study. The positive impact on locomotion coupled with the lack of safety concerns of the purified, expanded and banked HuCNS-SC in the immunodeficient SCI model provided the rationale for initiation of a clinical study in thoracic SCI subjects.

A progressive clinical study design was implemented by the company to test the safety and clinical effects of HuCNS-SC transplants in subjects with chronic thoracic (T2-T11) complete injury (American Spinal Injury Association (ASIA) classification A) progressing to subjects with incomplete (ASIA B or C) injury. The phase I/II trial was authorized by the SwissMedic regulatory authority and is being conducted by Dr Armin Curt (Balgrist Hospital, University of Zurich). The study will enroll 12 subjects who sustained a SCI within 3 to 12 months prior to cell transplantation. Each subject will receive a total fixed dose of approximately 20 million cells injected directly into the thoracic cord near the injury. Dosing of the first cohort, three AISA A subjects, has been completed and a 6-month interim evaluation performed (A Curt, Annual Scientific Meeting of the International Spinal Cord Society, September, 2012). To date, no safety concerns have arisen concerning the surgery or cellular transplant. Considerable gain in sensory function below the injury level was observed in two of the three subjects. This increased sensitivity to touch has evolved over time and was not anticipated in these very severely injured subjects since they were neurologically stable before transplant. Parallel changes in sensitivity to heat and electrical stimulation were also observed. Electrophysiological measurements across the injured spinal segments provided independent and objective measures of the change in sensory function. These data suggest that the transplanted human neural stem cells may be having a positive clinical effect in these severely injured subjects. The trial has just completed dosing of the first incomplete ASIA B subject and will continue to enroll eligible subjects until trial completion. Most human SCIs involve the cervical regions and preclinical studies are currently in progress with HuCNS-SC transplants into rodent 
models of cervical cord hemi-contusions in support of advancement to clinical testing.

\section{Retinal disorders}

The retina is an integral component of the CNS with complex neural circuitry involving transmission of signals from the photoreceptors to the brain through the optic nerve. Retinal diseases have long been viewed as a prime target for consideration in transplantation approaches because of ease of access, out-patient surgical procedure, the size of the eye, and the availability of non-invasive tests for visual function assessment following cell transplantation. Photoreceptors and retinal pigmented epithelial (RPE) cells derived from pluripotent stem cells have been the lead candidates for strategies based on cell replacement $[65,66]$.

Retinal protection using human neural stem/progenitor cells represents an alternative strategy for treating retinal diseases like dry age-related macular degeneration. The Royal College of Surgeons (RCS) rat has been used extensively as a model of retinal degeneration to assess efficacy of various cell types. The RCS rat has a mutation in the Mertk gene that causes disruption of the RPE cell's phagocytic activity, resulting in accumulation of toxic shed photoreceptor outer segments and eventual death of photoreceptors. Transplantation of human cortical neural progenitor cells into the subretinal space (between the photoreceptor and defective RPE cell layer) of the RCS rat resulted in the preservation of photoreceptors and rescue of visual function [67]. Recognizing the retinal protection conferred by the human neural progenitor cells in the study by Wang and colleagues [67], we asked whether HuCNS-SC might have a similar effect on host photoreceptors. When HuCNS-SC were transplanted into the subretinal space of RCS rats, the cells migrated within the subretinal space. Visual acuity was preserved to near normal levels and correlated to long-term protection of the photoreceptors in retinal areas adjacent to the transplanted human cells (Figure 5) [68]. Further analysis revealed that transplanted HuCNS-SC were able to phagocytose the shed outer segments, a task normally performed by healthy RPE cells. A Good Laboratory Practice safety and efficacy study was performed in RCS rats and results corroborated preservation of visual function without any safety concerns related to the transplanted cells. An Investigational New Drug was authorized by the FDA and a dose escalating phase I/II study is currently enrolling.

The study consists of two cohorts of 8 subjects (16 total). Cohort 1 will enroll subjects with best corrected visual acuity levels of $\leq 20 / 400$ in the treated eye. The second cohort will enroll subjects with best corrected visual acuity of $20 / 200$ to $20 / 100$. The subjects will receive oral immunosuppression for 3 months after surgery and will be followed for 1 year for any adverse events. Secondary assessments for preliminary efficacy will include visual acuity testing, and other detailed evaluations of ocular function and retinal imaging. At the conclusion of the study, subjects will be asked to participate in a separate 4-year long-term follow-up study.

\section{Targets for the future}

Many CNS indications (stroke, certain forms of cerebral palsy, Alzheimer's disease, traumatic brain injury and other disorders) may benefit from the neuroprotective or neural replacement properties of human neural stem cells. One of the most challenging diseases, Alzheimer's, will have a global impact on society as the number of affected individual's increases and healthcare costs skyrocket. Moreover, the recent failure of two drugs in late stage trials, targeted toward eliminating beta amyloid plaques (bapineuzumab and solanezumab) has left a void

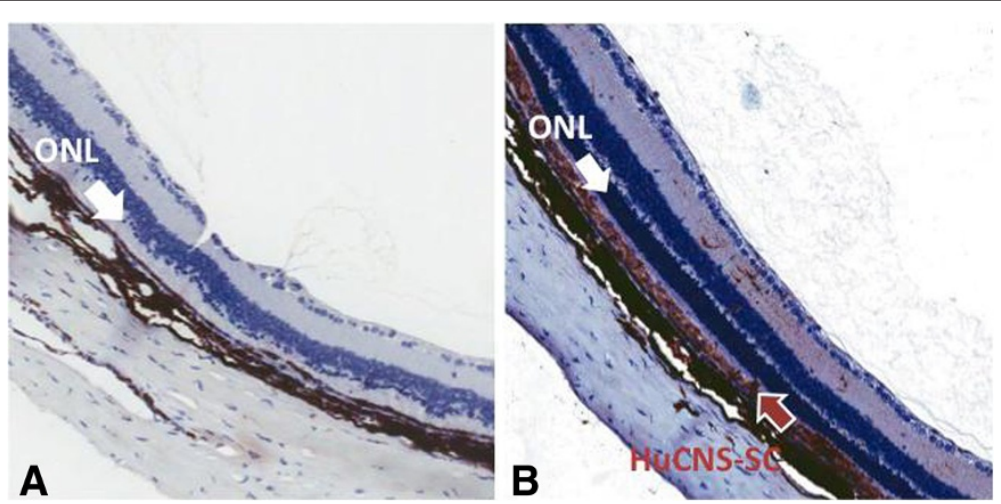

Figure 5 Human central nervous system stem cell (HuCNS-SC) subretinal transplantation preserves photoreceptors in treated Royal College of Surgeons rats. (A) Representative images of a retina cross-section showing that, at post-natal day 150 (about 4.5 months posttransplantation), only scattered photoreceptors are evident in the outer nuclear layer (ONL) of untreated eyes (the white arrow points to the remnants of the ONL, just underneath the thick inner nuclear layer). (B) In contrast, HuCNS-SC transplanted eyes have well preserved ONL adjacent to the HuCNS-SC. Reddish-brown outlined white arrow indicates the extent of HuCNS-SC engraftment, highlighted by SC121 staining. 
in treatment options for those suffering with this devastating neurodegenerative disease and highlights the critical need to explore novel treatment paradigms. Recent studies in two mouse models relevant to Alzheimer's disease, an inducible neuronal loss model (CAM/TetDTA) [69] and the 3xTg-AD mice (transgenic for mutant APP, PS1, and tau) [70], have shown that transplantation of mouse neural stem cells improved cognitive function. In the case of inducible neuronal loss, cognitive improvements correlated with protection of host neurons by murine neural stem cells. In the 3xTg-AD mice, increased synaptic density was noted and, in part, mediated through production of neurotrophic factors, such as brain-derived neurotrophic factor [71,72]. Transplantation of HuCNS-SC into aged 3xTg-AD mice has been performed and shows similar rescue in hippocampalbased memory deficits [73]. APP-SCID mice, which develop heavily plaque-laden brains $[74,75]$, were used to examine the effects of amyloid- $\beta$ (A $\beta$ ) plaques on the HuCNS-SC. These studies show long-term survival of the human cells within the heavily plaque-laden brain and suggest that $A \beta$ plaques are not toxic to the transplanted cells and that the therapeutic actions of these human cells may occur despite this pathology (G Carlson, personal communication). The observed increase in synaptic density in the $3 x \mathrm{Tg}$ - AD mouse brain following HuCNS-SC transplantation is of particular importance because clinical disability in Alzheimer's disease patients correlates with synaptic loss. Further studies are in progress to elucidate additional effects of these transplanted cells. Preliminary data from in vitro studies indicate that extracellular matrix deposited by $\mathrm{HuCNS}$ $\mathrm{SC}$ transplantation can promote neurite outgrowth from human neurons (Figure 6). Soluble $A \beta$ was reported to decrease neurite outgrowth from neuronal cultures and this coincides with reduced synapsin staining, indicative of synaptic loss. Accordingly, promotion of neurite outgrowth and protection from $\mathrm{A} \beta$-induced neuritic dystrophy is employed in phenotyping screening campaigns for Alzheimer's disease drug discovery [76]. As research progresses in the Alzheimer's disease field and more drugs targeting specific pathologies of Alzheimer's disease fail, the human neural stem cell becomes a more enticing candidate as a disease modifier by protecting host neurons and preserving synapse density. Any improvements in memory could have a significant impact on the quality of life for both patients and their caregivers and could alter current treatment paradigms for this growing health crisis.

\section{Conclusion}

The translational studies of HuCNS-SC speak to the biological activity of these cells in the brain, spinal cord and eye. To date, the preclinical studies in specific animal

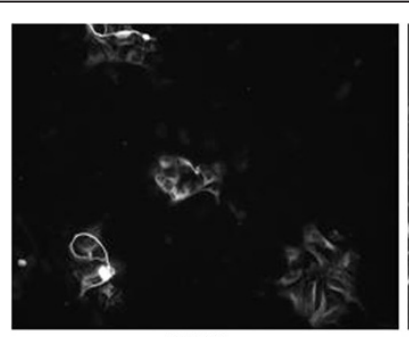

PLO

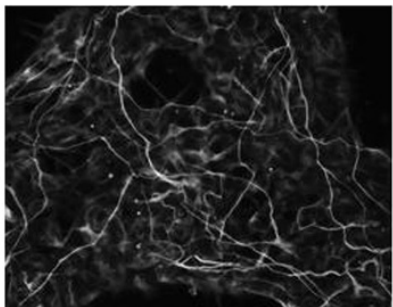

PLO + HUCNS-SCECM

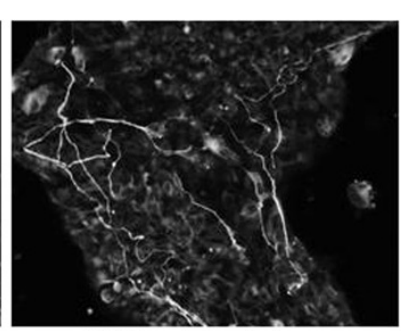

PLO + Laminin

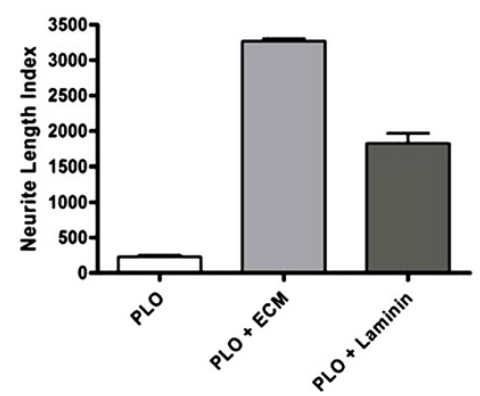

Figure 6 Human central nervous system stem cells (HuCNS-SC) are cultured adherently to confluence on poly-ornithine coated (PLO) plates and the cells removed by water lysis and repeated cell culture buffer washes, leaving only their deposited extracellular matrix (ECM) behind. Subsequently, a human neural stem cell type derived by a different protocol than the one used for the HuCNS-SC was seeded on the ECM-coated plates under neuronal differentiation-inducing conditions. Coating with PLO only and double-coating with PLO and laminin served as negative and positive controls for a neurite outgrowth-promoting substrate, respectively. The extent of neurite outgrowth was quantified with high-content assay analysis software after 96 hours. Neurite length index: total length of detected neurites in micrometers per 100 nuclei. Data represents the results of two independent experiments in five replicate wells. 
models have revealed biological properties of the HuCNS-SC similar to the emerging human data in the early clinical studies. The ultimate demonstration of a confirmed effect in patients will require controlled studies but the first results on safety and preliminary effects from these trials provide justification for continued human testing. Evidence of de novo myelin production in a hypomyelination disorder and improved sensation in $\mathrm{SCI}$ as clinical endpoints, unobserved with other interventions, emphasizes the potential of neural stem cell transplantation. If neural stem cell transplantation continues to show promising clinic data in altering disease progression, this approach could provide the novel therapeutic modality sorely needed for a spectrum of challenging neurological disorders.

Note: This article is part of a thematic series on Clinical applications of stem cells edited by Mahendra Rao. Other articles in the series can be found online at http://stemcellres.com/series/clinical.

\section{Abbreviations}

ASIA: American Spinal Injury Association; AB: Amyloid- $\beta$; CNS: Central nervous system; FA: Fractional anisotropy; FDA: Food and Drug Administration; HuCNS-SC: Human central nervous system stem cells; LSD: Lysosomal storage disease; MBP: Myelin basic protein; MRI: Magnetic resonance imaging; NCL: Neuronal ceroid lipofuscinosis; PCR: Polymerase chain reaction; PLP: Proteolipid protein; PMD: Pelizaeus-Merzbacher disease; RCS: Royal College of Surgeons; RPE: Retinal pigmented epithelial; SCI: Spinal cord injury; Shi: Shiverer; Shi-id: Immunodeficient Shi mice.

\section{Competing interests}

All authors are employees of StemCells, Inc. and receive Company stock.

Published: 29 August 2013

\section{References}

1. Spangrude GJ, Heimfeld S, Weissman IL: Purification and characterization of mouse hematopoietic stem cells. Science 1988, 241:58-62.

2. Morrison SJ, Weissman IL: The long-term repopulating subset of hematopoietic stem cells is deterministic and isolatable by phenotype. Immunity 1994, 1:661-673.

3. Baum CM, Weissman IL, Tsukamoto AS, Buckle AM, Peault B: Isolation of a candidate human hematopoietic stem-cell population. Proc Natl Acad Sci USA 1992, 89:2804-2808.

4. Morrison SJ, White PM, Zock C, Anderson DJ: Prospective identification, isolation by flow cytometry, and in vivo self-renewal of multipotent mammalian neural crest stem cells. Cell 1999, 96:737-749.

5. Nowak JA, Fuchs E: Isolation and culture of epithelial stem cells. Methods Mol Biol 2009, 482:215-232.

6. van der Flier $L G$, Clevers $\mathrm{H}$ : Stem cells, self-renewal, and differentiation in the intestinal epithelium. Annu Rev Physiol 2009, 71:241-260.

7. Cerletti M, Jurga S, Witczak CA, Hirshman MF, Shadrach JL, Goodyear $\mathrm{L}$, Wagers AJ: Highly efficient, functional engraftment of skeletal muscle stem cells in dystrophic muscles. Cell 2008, 134:37-47.

8. Al-Hajj M, Wicha MS, Benito-Hernandez A, Morrison SJ, Clarke MF: Prospective identification of tumorigenic breast cancer cells. Proc Nat Acad Sci USA 2003, 100:3983-3988.

9. Jiao J, Hindoyan A, Wang S, Tran LM, Goldstein AS, Lawson D, Chen D, Li Y, Guo C, Zhang B, Fazli L, Gleave M, Witte ON, Garraway IP, Wu H: Identification of CD166 as a surface marker for enriching prostate stem/ progenitor and cancer initiating cells. PLoS One 2012, 7:e42564.
10. Eriksson PS, Perfilieva E, Bjork-Eriksson T, Alborn AM, Nordborg C, Peterson DA, Gage FH: Neurogenesis in the adult human hippocampus. Nat Med 1998, 4:1313-1317.

11. Suh H, Deng W, Gage FH: Signaling in adult neurogenesis. Annu Rev Cell Dev Biol 2009, 25:253-275.

12. Gage FH: Mammalian neural stem cells. Science 2000, 287:1433-1438.

13. Svendsen CN, Caldwell MA, Shen J, ter Borg MG, Rosser AE, Tyers P, Karmiol $S$, Dunnett SB: Long-term survival of human central nervous system progenitor cells transplanted into a rat model of Parkinson's disease. Exp Neurol 1997, 148:135-146.

14. Brustle O, Choudhary K, Karram K, Huttner A, Murray K, Dubois-Dalcq M, McKay RD: Chimeric brains generated by intraventricular transplantation of fetal human brain cells into embryonic rats. Nat Biotechnol 1998, 16:1040-1044.

15. Carpenter MK, Cui X, Hu ZY, Jackson J, Sherman S, Seiger A, Wahlberg LU: In vitro expansion of a multipotent population of human neural progenitor cells. Exp Neurol 1999, 158:265-278

16. Uchida N, Buck DW, He D, Reitsma MJ, Masek M, Phan TV, Tsukamoto AS, Gage FH, Weissman IL: Direct isolation of human central nervous system stem cells. Proc Natl Acad Sci USA 2000, 97:14720-14725.

17. Pollard SM, Conti L, Sun Y, Goffredo D, Smith A: Adherent neural stem (NS) cells from fetal and adult forebrain. Cereb Cortex 2006, 16:1112-i120.

18. Kim HT, Kim IS, Lee IS, Lee JP, Snyder EY, Park KI: Human neurospheres derived from the fetal central nervous system are regionally and temporally specified but are not committed. Exp Neurol 2006, 199:222-235.

19. Brundin P, Barker RA, Parmar M: Neural grafting in Parkinson's disease: problems and possibilities. Prog Brain Res 2010, 184:265-294.

20. Politis M, Lindvall O: Clinical application of stem cell therapy in Parkinson's disease. BMC Med 2012, 10:1

21. Wijeyekoon R, Barker RA: The current status of neural grafting in the treatment of Huntington's disease. A review. Front Integr Neurosci 2011, 5:78,

22. Temple S: Division and differentiation of isolated CNS blast cells in microculture. Nature 1989, 340:471-473.

23. Cattaneo E, McKay R: Proliferation and differentiation of neuronal stem cells regulated by nerve growth factor. Nature 1990, 347:762-765.

24. Reynolds BA, Weiss S: Generation of neurons and astrocytes from isolated cells of the adult mammalian central nervous system. Science 1992, 255:1707-1710.

25. Kilpatrick TJ, Bartlett PF: Cloning and growth of multipotential neural precursors: requirements for proliferation and differentiation. Neuron 1993, 10:255-265.

26. Ray J, Peterson DA, Schinstine M, Gage FH: Proliferation, differentiation, and long-term culture of primary hippocampal neurons. Proc Natl Acad Sci USA 1993, 90:3602-3606.

27. McKay R: Stem cells in the central nervous system. Science 1997, 276:66-71.

28. Tamaki S, Eckert K, He D, Sutton R, Doshe M, Jain G, Tushinski R, Reitsma M, Harris B, Tsukamoto A, Gage F, Weissman I, Uchida N: Engraftment of sorted/expanded human central nervous system stem cells from fetal brain. J Neurosci Res 2002, 69:976-986.

29. Guzman R, Uchida N, Bliss TM, He D, Christopherson KK, Stellwagen D, Capela A, Greve J, Malenka RC, Moseley ME, Palmer TD, Steinberg GK: Longterm monitoring of transplanted human neural stem cells in developmental and pathological contexts with MRI. Proc Natl Acad Sci USA 2007, 104:10211-10216.

30. Chen Y, Liu L: Modern methods for delivery of drugs across the bloodbrain barrier. Adv Drug Deliv Rev 2012, 64:640-665.

31. Shihabuddin LS, Aubert I: Stem cell transplantation for neurometabolic and neurodegenerative diseases. Neuropharmacology 2010, 58:845-854.

32. Snyder EY, Macklis JD: Multipotent neural progenitor or stem-like cells may be uniquely suited for therapy for some neurodegenerative conditions. Clin Neurosci 1995, 3:310-316.

33. Lacorazza HD, Flax JD, Snyder EY, Jendoubi M: Expression of human betahexosaminidase alpha-subunit gene (the gene defect of Tay-Sachs disease) in mouse brains upon engraftment of transduced progenitor cells. Nat Med 1996, 2:424-429.

34. Buchet D, Serguera C, Zennou V, Charneau P, Mallet J: Long-term expression of beta-glucuronidase by genetically modified human neural progenitor cells grafted into the mouse central nervous system. Mol Cell Neurosci 2002, 19:389-401. 
35. Meng XL, Shen JS, Ohashi T, Maeda H, Kim SU, Eto Y: Brain transplantation of genetically engineered human neural stem cells globally corrects brain lesions in the mucopolysaccharidosis type VII mouse. J Neurosci Res 2003, 74:266-277.

36. Shihabuddin LS, Numan S, Huff MR, Dodge JC, Clarke J, Macauley SL, Yang W, Taksir TV, Parsons G, Passini MA, Gage FH, Stewart GR: Intracerebral transplantation of adult mouse neural progenitor cells into the Niemann-Pick-A mouse leads to a marked decrease in lysosomal storage pathology. J Neurosci 2004, 24:10642-10651.

37. Lee JP, Jeyakumar M, Gonzalez R, Takahashi H, Lee PJ, Baek RC, Clark D, Rose H, Fu G, Clarke J, McKercher S, Meerloo J, Muller FJ, Park KI, Butters TD, Dwek RA, Schwartz P, Tong G, Wenger D, Lipton SA, Seyfried TN, Platt FM, Snyder EY: Stem cells act through multiple mechanisms to benefit mice with neurodegenerative metabolic disease. Nat Med 2007, 13:439-447.

38. Tamaki SJ, Jacobs Y, Dohse M, Capela A, Cooper JD, Reitsma M, He D, Tushinski R, Belichenko PV, Salehi A, Mobley W, Gage FH, Huhn S, Tsukamoto AS, Weissman IL, Uchida N: Neuroprotection of host cells by human central nervous system stem cells in a mouse model of infantile neuronal ceroid lipofuscinosis. Cell Stem Cell 2009, 5:310-319.

39. Jeyakumar M, Lee JP, Sibson NR, Lowe JP, Stuckey DJ, Tester K, Fu G, Newlin $R$, Smith DA, Snyder EY, Platt FM: Neural stem cell transplantation benefits a monogenic neurometabolic disorder during the symptomatic phase of disease. Stem Cells 2009, 27:2362-2370.

40. Cooper JD, Russell C, Mitchison HM: Progress towards understanding disease mechanisms in small vertebrate models of neuronal ceroid lipofuscinosis. Biochim Biophys Acta 2006, 1762:873-889.

41. Wong AM, Rahim AA, Waddington SN, Cooper JD: Current therapies for the soluble lysosomal forms of neuronal ceroid lipofuscinosis. Biochem Soc Trans 2010, 38:1484-1488.

42. Gupta P, Soyombo AA, Atashband A, Wisniewski KE, Shelton JM, Richardson JA, Hammer RE, Hofmann SL: Disruption of PPT1 or PPT2 causes neuronal ceroid lipofuscinosis in knockout mice. Proc Natl Acad Sci USA 2001, 98:13566-13571.

43. Sleat DE, Wiseman JA, El-Banna M, Kim KH, Mao Q, Price S, Macauley SL, Sidman RL, Shen MM, Zhao Q, Passini MA, Davidson BL, Stewart GR, Lobel $P$ : A mouse model of classical late-infantile neuronal ceroid lipofuscinosis based on targeted disruption of the CLN2 gene results in a loss of tripeptidyl-peptidase I activity and progressive neurodegeneration. J Neurosci 2004, 24:9117-9126.

44. Selden NR, Al-Uzri A, Huhn SL, Koch TK, Sikora DM, Nguyen-Driver MD Guillaume DJ, Koh JL, Gultekin SH, Anderson JC, Vogel H, Sutcliffe TL, Jacobs Y, Steiner RD: Central nervous sytem stem cell transplantation for children with neuronal ceroid lipofuscinosis. J Neurosurg Pediatr 2013, 11:643-652.

45. Jacobs Y, Selden N, Al-Uzri A, Koch T, Vogel H, Huhn S, Uchida N, DalmaWeiszhausz D, Tsukamoto A, Steiner R: Long-term survival and migration of allogeneic human central nervous system stem cells following intracerebral transplantation in neuronal ceroid lipofuscinosis [abstract]. ISSCR 2011 Annual Meeting; Toronto, ON, Canada: June 2011, page 44 [http://www.isscr.org/docs/ default-source/am2011/isscr-2011-friday-abstracts.pdf?sfvrsn=2].

46. Saunders CJ, Miller NA, Soden SE, Dinwiddie DL, Noll A, Alnadi NA, Andraws N, Patterson ML, Krivohlavek LA, Fellis J, Humphray S, Saffrey P, Kingsbury Z, Weir JC, Betley J, Grocock RJ, Margulies EH, Farrow EG, Artman M, Safina NP, Petrikin JE, Hall KP, Kingsmore SF: Rapid whole-genome sequencing for genetic disease diagnosis in neonatal intensive care units. Sci Trans/ Med 2012, 4:154ra135.

47. Uchida N, Chen K, Dohse M, Hansen KD, Dean J, Buser JR, Riddle A, Beardsley DJ, Wan Y, Gong X, Nguyen T, Cummings BJ, Anderson AJ, Tamaki SJ, Tsukamoto A, Weissman IL, Matsumoto SG, Sherman LS, Kroenke CD, Back SA: Human neural stem cells induce functional myelination in mice with severe dysmyelination. Sci Trans/ Med 2012, 4:155ra136.

48. Goldman SA, Schanz S, Windrem MS: Stem cell-based strategies for treating pediatric disorders of myelin. Hum Mol Genet 2008, 17:R76-R83.

49. Goldman SA, Sim FJ: Cell-based therapies for disorders of the brain and spinal cord. Neurotherapeutics 2011, 8:537-538.

50. Duncan ID, Kondo Y, Zhang SC: The myelin mutants as models to study myelin repair in the leukodystrophies. Neurotherapeutics 2011, 8:607-624

51. Gansmuller A, Clerin E, Kruger F, Gumpel M, Lachapelle F: Tracing transplanted oligodendrocytes during migration and maturation in the shiverer mouse brain. Glia 1991, 4:580-590.
52. Yandava BD, Billinghurst LL, Snyder EY: "Global" cell replacement is feasible via neural stem cell transplantation: evidence from the dysmyelinated shiverer mouse brain. Proc Natl Acad Sci USA 1999, 96:7029-7034

53. Windrem MS, Nunes MC, Rashbaum WK, Schwartz TH, Goodman RA, McKhann G, Roy NS, Goldman SA: Fetal and adult human oligodendrocyte progenitor cell isolates myelinate the congenitally dysmyelinated brain. Nat Med 2004, 10:93-97.

54. Cummings BJ, Uchida N, Tamaki SJ, Salazar DL, Hooshmand M, Summers R, Gage FH, Anderson AJ: Human neural stem cells differentiate and promote locomotor recovery in spinal cord-injured mice. Proc Natl Acad Sci USA 2005, 102:14069-14074

55. Maire CL, Buchet D, Kerninon C, Deboux C, Baron-Van Evercooren A, NaitOumesmar B: Directing human neural stem/precursor cells into oligodendrocytes by overexpression of Olig2 transcription factor. $J$ Neurosci Res 2009, 87:3438-3446.

56. Buchet D, Garcia C, Deboux C, Nait-Oumesmar B, Baron-Van Evercooren A: Human neural progenitors from different foetal forebrain regions remyelinate the adult mouse spinal cord. Brain 2011, 134:1168-1183.

57. Windrem MS, Schanz SJ, Guo M, Tian GF, Washco V, Stanwood N, Rasband M, Roy NS, Nedergaard M, Havton LA, Wang S, Goldman SA: Neonatal chimerization with human glial progenitor cells can both remyelinate and rescue the otherwise lethally hypomyelinated shiverer mouse. Cell Stem Cell 2008, 2:553-565.

58. Sim FJ, McClain CR, Schanz SJ, Protack TL, Windrem MS, Goldman SA: CD140a identifies a population of highly myelinogenic, migrationcompetent and efficiently engrafting human oligodendrocyte progenitor cells. Nat Biotechnol 2011, 29:934-941.

59. Garbern JY: Pelizaeus-Merzbacher disease: genetic and cellular pathogenesis. Cell Mol Life Sci 2007, 64:50-65.

60. Gupta N, Henry RG, Strober J, Kang SM, Lim DA, Bucci M, Caverzasi E, Gaetano L, Mandelli ML, Ryan T, Perry R, Farrell J, Jeremy RJ, Ulman M, Huhn SL, Barkovich AJ, Rowitch DH: Neural stem cell engraftment and myelination in the human brain. Sci Trans/ Med 2012, 4:155ra137.

61. Cummings BJ, Uchida N, Tamaki SJ, Anderson AJ: Human neural stem cell differentiation following transplantation into spinal cord injured mice: association with recovery of locomotor function. Neurol Res 2006, 28:474481.

62. Hooshmand MJ, Sontag CJ, Uchida N, Tamaki S, Anderson AJ, Cummings BJ: Analysis of host-mediated repair mechanisms after human CNS-stem cell transplantation for spinal cord injury: correlation of engraftment with recovery. PLoS One 2009, 4:e5871

63. Salazar DL, Uchida N, Hamers FP, Cummings BJ, Anderson AJ: Human neural stem cells differentiate and promote locomotor recovery in an early chronic spinal cord injury NOD-scid mouse model. PLoS One 2010, 5:e12272.

64. Hofstetter CP, Holmstrom NA, Lilja JA, Schweinhardt P, Hao J, Spenger C Wiesenfeld-Hallin Z, Kurpad SN, Frisen J, Olson L: Allodynia limits the usefulness of intraspinal neural stem cell grafts; directed differentiation improves outcome. Nat Neurosci 2005, 8:346-353.

65. Rowland TJ, Buchholz DE, Clegg DO: Pluripotent human stem cells for the treatment of retinal disease. J Cell Physiol 2012, 227:457-466.

66. Stern $\mathrm{JH}$, Temple S: Stem cells for retinal replacement therapy. Neurotherapeutics 2012, 8:736-743.

67. Wang S, Girman S, Lu B, Bischoff N, Holmes T, Shearer R, Wright LS, Svendsen CN, Gamm DM, Lund RD: Long-term vision rescue by human neural progenitors in a rat model of photoreceptor degeneration. Invest Ophthalmol Vis Sci 2008, 49:3201-3206.

68. McGill TJ, Cottam B, Lu B, Wang S, Girman S, Tian C, Huhn SL, Lund RD, Capela A: Transplantation of human central nervous system stem cells - neuroprotection in retinal degeneration. Eur J Neurosci 2012, 35:468-477.

69. Yamasaki TR, Blurton-Jones M, Morrissette DA, Kitazawa M, Oddo S, LaFerla FM: Neural stem cells improve memory in an inducible mouse model of neuronal loss. J Neurosci 2007, 27:11925-11933.

70. Oddo S, Caccamo A, Shepherd JD, Murphy MP, Golde TE, Kayed R, Metherate R, Mattson MP, Akbari Y, LaFerla FM: Triple-transgenic model of Alzheimer's disease with plaques and tangles: intracellular Abeta and synaptic dysfunction. Neuron 2003, 39:409-421.

71. Blurton-Jones M, Kitazawa M, Martinez-Coria H, Castello NA, Muller FJ, Loring JF, Yamasaki TR, Poon WW, Green KN, LaFerla FM: Neural stem cells 
improve cognition via BDNF in a transgenic model of Alzheimer disease. Proc Natl Acad Sci USA 2009, 106:13594-13599.

72. Chen WW, Blurton-Jones M: Concise review: can stem cells be used to treat or model Alzheimer disease? Stem Cells 2012, 30:2612-2618.

73. Blurton-Jones M, Ager R, Nerhus J, Agazaryan A, Huhn S, Capela A, LaFerla F: Restoration of memory in mouse models of Alzheimer disease and neuronal loss: a new paradigm using human neural stem cell transplantation [abstract]. Alzheimer's Association International Conference 2012 [http://download.journals.elsevierhealth.com/pdfs/journals/1552-5260/ PIIS1552526012017013.pdf].

74. Carlson GA, Borchelt DR, Dake A, Turner S, Danielson V, Coffin JD, Eckman C, Meiners J, Nilsen SP, Younkin SG, Hsiao KK: Genetic modification of the phenotypes produced by amyloid precursor protein overexpression in transgenic mice. Hum Mol Genet 1997, 6:1951-1959.

75. Chishti MA, Yang DS, Janus C, Phinney AL, Horne P, Pearson J, Strome R, Zuker N, Loukides J, French J, Turner S, Lozza G, Grilli M, Kunicki S, Morissette C, Paquette J, Gervais F, Bergeron C, Fraser PE, Carlson GA, George-Hyslop PS, Westaway D: Early-onset amyloid deposition and cognitive deficits in transgenic mice expressing a double mutant form of amyloid precursor protein 695. J Biol Chem 2001, 276:21562-21570.

76. Nguyen L, Wright S, Lee M, Ren Z, Sauer JM, Hoffman W, Zago W, Kinney GG, Bova MP: Quantifying amyloid beta (Abeta)-mediated changes in neuronal morphology in primary cultures: implications for phenotypic screening. J Biomol Screen 2012, 17:835-842.

\section{doi:10.1186/scrt313}

Cite this article as: Tsukamoto et al: Clinical translation of human neural stem cells. Stem Cell Research \& Therapy 2013 4:102. 